\title{
CAPITULO 37
}

\section{NOVOS TEMPOS, NOVAS PRÁTICAS: RELATO DE ESTÁGIO REMOTO SUPERVISIONADO EM PSICOLOGIA DURANTE A PANDEMIA DE COVID-19}

\author{
Carolina de Paula Augusto Feitosa ${ }^{1}$, Vanessa Pereira Lima ${ }^{2}$, \\ ${ }^{1}$ Universidade Estácio de Sá - UNESA (carolinadepaula0702@ hotmail.com) \\ ${ }^{2}$ Universidade Ceuma, (vane_lima14@ hotmail.com)
}

\section{Resumo}

O presente trabalho tem como objetivo discorrer sobre a experiência em estágio remoto supervisionado na área de Psicologia, realizado por meio do Serviço de Psicologia Aplicada (SPA), na Universidade Estácio de Sá (UNESA), realizado entre o $8^{\circ}$ e o $10^{\circ}$ período, mais especificamente, entre outubro de 2020 e dezembro de 2021. A partir do estudo, foi possível constatar algumas dificuldades nos atendimentos, decorrentes do próprio período de isolamento social. Dentre elas, pode-se citar problemas de conexão, dificuldades para ter privacidade e ambientes confortáveis para realização das sessões, por parte dos pacientes, além da própria mudança do setting terapêutico, que acaba criando desafios para ambas as partes, paciente e terapeuta. Nesse cenário, o que ganhou destaque e se mostrou relevante foi a busca por constante adaptação, os esforços realizados por ambas as partes e primordialmente, a preparação de um adequado setting terapêutico.

Palavras-chave: Psicologia; Atendimento psicológico; Isolamento social; COVID-19.

Área Temática: COVID-19.

E-mail do autor principal: carolinadepaula0702@hotmail.com

\section{INTRODUÇÃO}

Segundo a OMS (Organização Mundial da Saúde), o Coronavírus, também conhecido como COVID-19, é uma doença infecciosa causada pelo vírus SARS-CoV-2. De acordo com a OPAS (Organização Pan-Americana da Saúde), esta nova cepa, que ainda não havia sido identificada em humanos, foi identificada por autoridades chinesas em Janeiro de 2020 e em março do mesmo ano, a OMS classificou a situação como uma pandemia. Os principais sintomas da doença são, segundo a OMS: febre, tosse, cansaço e perda de paladar. Sintomas mais graves também podem ser detectados, como dificuldade para respirar ou falta de ar, perda

\section{E - book Pesquisa e Tecnologia: Protagonismo e} Inovações 
da fala, mobilidade ou confusão e dores no peito.

Diante da gravidade da doença e de sua fácil transmissão, o mundo teve de se habituar ao isolamento social, uma das medidas mais eficazes para diminuir o contágio da doença. Apesar de ser uma medida necessária, isso fez com que milhares de pessoas que antes viviam suas vidas normalmente, passassem a se manter em casa em tempo integral. Dinâmicas que antes eram naturais e que auxiliavam na vivência das pessoas, se tornaram raras e a falta disso pode ter causado um grande impacto na saúde mental das pessoas.

Tendo em vista um cenário caótico de medos, angústias e incertezas por conta da doença, o suporte e atendimento psicológico online ganharam ainda mais importância e se apresentaram como maneiras de acolher psicologicamente os indivíduos em crise diante dessa situação. Isso pois o psicólogo precisou se adaptar a essa situação, dado que a demanda tendeu a aumentar. $\mathrm{O}$ atendimento psicológico remoto se apresentou então como uma possibilidade de atuação para estagiários naquele momento.

O objetivo deste trabalho é apresentar a experiência de estágio supervisionado remoto de uma formanda do curso de Psicologia da (UNESA) Universidade Estácio de Sá durante o período de pandemia de COVID-19, fazendo relações com as regulamentações existentes acerca do atendimento psicológico de forma remota, bem como levantando reflexões acerca dessa prática que se tornou necessária.

\section{MÉTODO}

Para a construção deste trabalho, considera-se a experiência de uma estagiária de psicologia clínica nos atendimentos psicológicos remotos realizados através do Serviço de Psicologia Aplicada (SPA) da UNESA, do $8^{\circ}$ ao $10^{\circ}$ período, entre outubro de 2020 e dezembro de 2021, incluídos nessa duração os recessos e férias próprios da instituição. Como mencionado anteriormente, em virtude da pandemia de COVID-19, os estágios, que antes eram realizados de maneira presencial no SPA da universidade, passaram a acontecer de maneira virtual, assim como as supervisões de estágio com professores e colegas.

A estagiária teve, durante o período citado, apenas duas pacientes, levando em consideração o grande número de casos para que cada professor deveria oferecer supervisão, além do fato de que é recomendado pelos mesmos que durante esse processo de aprendizagem da prática clínica, os alunos dirijam suas práticas e atenção a poucos casos.

Após orientações da professora supervisora de estágio, o contato inicial com as Inovações 
pacientes se deu via aplicativo de mensagens de texto, onde a estagiária se apresentou, explicou o motivo do contato, falou brevemente sobre como se dão os atendimentos online e questionou se ainda havia, por parte do paciente, interesse em ser atendido, visto que, por conta da grande demanda para os atendimentos psicológicos, muitos inscritos aguardam meses para receberem alguma resposta. Após a confirmação das inscritas, foi agendado, com base na disponibilidade da estagiária e da paciente, atendimentos semanais, que aconteciam sempre no mesmo dia e horário, com duração de 50 minutos cada.

Foram realizados, no total, 30 atendimentos, sendo 8 no $8^{\circ}$ período, com apenas uma paciente, 11 no $9^{\circ}$ período, com duas pacientes, sendo 4 para uma e 7 para a outra e 11 no $10^{\circ}$ período, com uma paciente.

Portanto, este trabalho se configura como um relato de experiência.

\section{RESULTADOS E DISCUSSÃO}

A situação de pandemia impactou diversos setores da vida, e as suas implicações trouxeram uma série de mudanças para a vida cotidiana dos indivíduos. Em que pese a importância da quarentena para minimizar os efeitos e o contágio, quando se decide analisar tal circunstância, é possível observar que a quarentena possui alguns efeitos negativos, que incluem estresse pós-traumático, confusão e raiva. (Schmidt et al 2020, p. 3 apud Brooks et $a l, 2020)$ Assim, essas consequências negativas do isolamento social podem constituir um empecilho para o bem-estar das pessoas, que já estava sendo acometido pela pandemia de Covid-19.

Nesse cenário, diversas conjunturas merecem atenção. Por exemplo, de acordo com Schmidt et al (2020, p. 3 apud Shimizu, 2020), a situação que aponta para uma possibilidade de discriminação com relação aos chineses, por conta de sua nacionalidade, como se eles naturalmente transmitissem o vírus. Essa visão discriminatória do grupo pode fazer com que as pessoas tenham que lidar com o preconceito, o que pode criar um cenário de sofrimento psicológico para eles.

Ademais, é importante refletir que alguns grupos e uma própria classe social podem ficar mais expostos ao vírus, o que impede o isolamento social, mas não exclui a possibilidade de implicações psicológicas negativas. É possível observar que essa situação também pode gerar preocupações com a escassez de suprimentos e perdas financeiras (Schmidt et al (2020, p. 3 apud Shojaei \& Masoumi, 2020), que certamente também impactam o bem-estar Inovações 
psicológico da população.

As implicações na saúde mental das pessoas em decorrência da pandemia e do isolamento social não se esgotam a essas hipóteses, mas citá-las parece suficiente para demonstrar a necessidade de atuação do profissional de Psicologia. Pois como assevera Schmidt B, et al. (2020, p. 3): "Analisados em conjunto, todos esses fatores remetem à relevância de intervenções psicológicas alinhadas às necessidades emergentes no atual contexto de pandemia".

Essa situação demanda ações rápidas que tentem, mesmo que pareça impossível, acompanhar o caminhar da pandemia de Covid-19, pois o contágio pode trazer sequelas para a vida dos indivíduos.

Neste contexto, tendo em vista a necessidade de desenvolver respostas para lidar com essa situação, em 31 de março de 2020, foi publicada a Portaria n. 639 do Ministério da Saúde, que tratou de uma ação estratégica para cadastrar e, especialmente, capacitar profissionais da área da saúde para enfrentar a pandemia do Covid-19.

No parágrafo $1^{\circ}$ do art. $1^{\circ}$ da Portaria, se observa que a psicologia foi considerada como área de saúde, do modo que deveria ser. A ação estratégica foi descrita como aquela a ser posta em prática através (Ministério da Saúde, 2020): I - da criação de um cadastro geral de profissionais da área da saúde habilitados para
atuar em território nacional, que poderá ser consultado pelos entes federados, em caso
de necessidade, para orientar suas ações de enfrentamento à COVID-19; e
II - da capacitação dos profissionais da área de saúde nos protocolos oficiais de
enfrentamento à COVID-19, aprovados pelo Centro de Operações de Emergências em
Saúde Pública (COE-nCoV).

Assim, o cenário social era um que demandava adaptações para que a vida continuasse, e para que os efeitos da pandemia fossem minimizados.

Ressaltamos a Resolução do Conselho Federal de Psicologia n. 11, de 11 de maio de 2018, que visou regulamentar a prestação de serviços psicológicos feitos por meios de tecnologias da informação e da comunicação. A Resolução dispôs de forma sucinta porém objetiva sobre a atividade do psicólogo a ser prestada de forma remota. Inicialmente, destaca que os serviços psicológicos a serem realizados englobam:

Art. $2^{\circ}$. São autorizadas a prestação dos seguintes serviços psicológicos realizados por meios tecnológicos da informação e comunicação, desde que não firam as disposições do Código de Ética Profissional da psicóloga e do psicólogo a esta Resolução:

I. As consultas e/ou atendimentos psicológicos de diferentes tipos de maneira síncrona ou assíncrona;

II. Os processos de Seleção de Pessoal;

III. Utilização de instrumentos psicológicos devidamente regulamentados por resolução pertinente, sendo que os testes psicológicos devem ter parecer favorável do

\section{E - book Pesquisa e Tecnologia: Protagonismo e Inovações}


Sistema de Avaliação de Instrumentos Psicológicos (SATEPSI), com padronização e normatização específica para tal finalidade.

IV. A supervisão técnica dos serviços prestados por psicólogas e psicólogos nos mais diversos contextos de atuação" (Conselho Federal de Psicologia, 2018).

Ainda, evidenciou o que considera atendimento ou consulta psicológica, destacando ser

(...) o conjunto sistemático de procedimentos, por meio da utilização de métodos e técnicas psicológicas do qual se presta um serviço nas diferentes áreas de atuação da Psicologia com vistas à avaliação, orientação e/ou intervenção em processos individuais e grupais. (Conselho Federal de Psicologia, 2018)

Sendo que isso foi o realizado nas práticas psicológicas experienciadas no estágio objeto do presente estudo.

À época, tornou-se evidente a preocupação com regulamentar os serviços prestados por meio da internet, o que certamente auxiliou no cenário de pandemia, tendo em vista que a existência de uma regulamentação prévia ao cenário de pandemia traz à tona uma possibilidade de o profissional já estar um pouco preparado a atuar deste modo.

O Conselho Federal de Psicologia publicou então, em 26 de março de 2020 a Resolução n. 4, que versou sobre os atendimentos psicológicos prestados por meio de tecnologia da informação e da comunicação. Nesta disposição, é possível observar que o profissional de Psicologia poderia atuar de modo remoto, devendo se atentar ao Código de Ética Profissional da área. Além disso, para que fosse viável a realização de atendimentos psicológicos, a resolução dispôs sobre a necessidade de cadastro prévio na plataforma e-Psi do Conselho de Psicologia da região do profissional. Além disso, segundo a Resolução:

Art. $4^{\circ}$. Ficam suspensos os Art. $3^{\circ}$, Art. $4^{\circ}$, Art. $6^{\circ}$, Art. $7^{\circ}$ e Art. $8^{\circ}$ da Resolução CFP $\mathrm{n}^{\circ} 11$, de 11 de Maio de 2018, durante o período de pandemia do COVID-19 e até que sobrevenha Resolução do CFP sobre serviços psicológicos prestados por meios de tecnologias da informação e da comunicação. (Conselho Federal de Psicologia, 2020)

Entretanto, também há que se falar dos desafios que o momento de pandemia trouxe para a prática psicológica.

A experiência de estagiar de maneira virtual, em virtude da pandemia, foi desafiadora. Mesmo com todas as orientações, preparações e dicas da professora supervisora de estágio, este momento foi extremamente desafiador, pois antes mesmo do primeiro atendimento, já era possível estar apreensiva por uma série de questões, como: o início do estágio e primeiro atendimento propriamente dito, que costuma provocar certa apreensão nos estudantes de Psicologia; o momento atual, em virtude da pandemia, que trazia à época muitas incertezas quanto ao rumo da doença e uma possível cura; e as possíveis dificuldades que um processo

\section{E - book Pesquisa e Tecnologia: Protagonismo e Inovações}


psicoterapêutico online poderia oferecer, considerando que enquanto estagiária, nunca havia tido uma experiência semelhante.

Com isso, reforçamos a importância do futuro terapeuta estar em dia com seu próprio processo psicoterapêutico, tendo um espaço onde possa falar abertamente sobre os medos e angústias inerentes à atuação.

Os atendimentos psicológicos remotos se configuraram como uma necessidade para muitas pessoas, inclusive para quem nunca havia feito terapia antes, como as pacientes atendidas durante o estágio. Apesar disso, é importante ressaltar que tal experiência também foi permeada por algumas dificuldades: a mudança no setting terapêutico, não ser possível observar todos os comportamentos do paciente, problemas de conectividade durante os atendimentos, como queda de internet e rede, interrupções por parte de familiares que por vezes entravam nos cômodos onde era realizado o atendimento, mesmo com as orientações para que o paciente solicitasse à família que respeitasse sua privacidade. Importante ressaltar que foi sugerido, pela estagiária, que os atendimentos fossem realizados em um local onde o paciente tivesse uma boa conexão de internet, privacidade e que se possível, utilizasse fones de ouvido.

Dentre os desafios citados brevemente, cumpre destacar que a mudança no setting terapêutico cria uma situação de encontro com o novo, o que provoca uma necessidade de adaptação muito grande, primeiramente para o psicoterapeuta, que precisa trabalhar para que o seu setting terapêutico continue sendo acolhedor o bastante para que o paciente se sinta preparado e aberto para a terapia.

O setting terapêutico é preponderante para que a relação entre terapeuta e paciente seja um ambiente seguro para que ambos consigam caminhar para que a psicoterapia surta efeitos.

Nas palavras de Eva Maria Migliavacca (2008, p. 5):

(...) o setting também é um conceito. De fato, de um ponto de vista da naturalidade
dos encontros humanos, nada pode ser mais artificial do que marcar hora, data e
combinar pagamento para conversar sobre a vida psíquica! No entanto, nesse
ambiente, desenrola-se um drama real, intenso e tenso, numa relação profundamente
humana e de caráter transformador. Por isso, no conceito setting se inclui a
consideração do que acontece dentro dele como sendo diverso de tudo que acontece
fora dele. Tanto que, se o setting é quebrado pelo analista, evidencia-se que um
desastre ocorreu, primeiro no psiquismo e depois na realidade transformada em atos.
Nesse sentido, o setting significa uma postura, uma atitude que considera que o
conhecimento se dá não pela atuaçãa, mas pela percepção das necessidades reais do
paciente e pela sua tradução em termos da vida psíquica.

Deste modo, na abordagem clínica, dentre outros fatores, o sucesso da psicoterapia se pauta muito em como o setting terapêutico é definido, trabalhado e mantido durante a terapia.

\section{E - book Pesquisa e Tecnologia: Protagonismo e Inovações}


Percebe-se, portanto, que um setting bem preparado pode auxiliar no êxito das sessões.

À vista disso, faz-se a reflexão em torno de um novo setting terapêutico trazido pela pandemia, que se impôs inicialmente como a única forma de realização dos encontros entre paciente e terapeuta.

Essa mudança de setting trouxe uma série de desafios, dentre os quais foi possível observar na experiência que é necessário que o profissional se adapte. Cabe ao profissional tentar ao máximo fazer o ambiente ser acolhedor para o paciente, de modo que a realidade cheia de limitações trazida pela pandemia não se constitua como um verdadeiro empecilho para a realização das sessões. Em outras palavras, foi possível ver na prática a necessidade de um trabalho do terapeuta a fim de tornar possível que a vida psíquica venha à tona.

Dentre os desafios da mudança de setting, cita-se o fato de não ser possível observar todos os comportamentos do paciente, o que dificulta a leitura do terapeuta sobre todos os fatores envolvendo o que está sendo posto como objeto de análise.

Isso certamente impõe limites para a leitura do terapeuta, que deseja ter uma visão ampla do paciente, fazendo uma análise do que é dito e do que não é dito.

Além desses fatores, há que se ressaltar a necessidade de preparação de um setting em que o terapeuta também leve em consideração a sua própria capacidade naquele momento, não sendo recomendado demandar de si, enquanto terapeuta, mais do que consegue oferecer. Até mesmo pois, conforme traz Glória Barros (2013, p. 71) ao versar sobre o setting na clínica:

O Setting analítico tem a ver com os dois integrantes do processo analítico: analista e paciente. A sensibilidade do analista é fundamental, e isso tem que levar em consideração tanto as características do paciente quanto as do analista, que se derivam de seu próprio percurso.

Além destes, um dos maiores desafios diz respeito à falta de privacidade e ambiente adequado para que o paciente possibilite ao psicólogo o conhecimento sobre a sua vivência, ou até mesmo a intervenção do mesmo em situações que assim exijam.

Situações de interrupções por parte de familiares que por vezes entravam nos cômodos onde era realizado o atendimento demonstraram desafios para a manutenção do contato entre analista e analisando.

Conforme foi dito, foram feitas as orientações para que o paciente solicitasse à família que respeitasse sua privacidade, o que nem sempre era respeitado.

Ainda, de cunho técnico, há que se citar eventuais problemas de conectividade no decorrer dos atendimentos, por exemplo interrupção no sinal de internet e rede. O que também ocorreu nas práticas vivenciadas, constituindo-se tanto como um fator de preocupação do

\section{E - book Pesquisa e Tecnologia: Protagonismo e Inovações}


terapeuta com relação à interrupção dessa ação de desenrolar a vida psíquica do paciente, quanto como situações que não impactaram diretamente na experiência clínica.

Isso porque apesar da situação de pandemia ser bastante delicada e trazer as consequências e receios comuns a ambos os lados, paciente e terapeuta, observa-se também que é possível que os pacientes consigam se sentir confortáveis no ambiente terapêutico. Tal êxito pode ser atribuído a um trabalho mútuo de manutenção de um setting que ajude ambos.

\section{CONCLUSÃO}

Diante de toda a experiência relatada, foi possível observar algumas das diversas circunstâncias trazidas pelo COVID-19, e que trouxeram à tona dificuldades a serem experienciadas pelos indivíduos. Inerente a esse novo normal, torna-se necessário que as pessoas continuem cuidando de sua saúde mental, o que pede pela adaptação da prática psicológica na realidade vivenciada pelos indivíduos.

Nesse cenário, a adaptação se mostrou como um fator preponderante para a continuidade dos atendimentos, além de outros fatores que se mostraram importantes de serem analisados. O setting terapêutico é um conceito o qual o terapeuta deve sempre estar atento a desenvolver. Entretanto, também se faz necessário que o paciente contribua, na medida do possível, para que a sessão tenha êxito, entendendo a importância de estar sozinho, de valorizar a sua privacidade e estar em ambientes tranquilos. Pois assim se pode esperar uma sessão que supra as necessidades do paciente, ainda mais em um contexto pandêmico.

As palavras que podem sintetizar a prática vivenciada são necessidade de adaptação e de contribuição mútua para que a terapia atingisse os seus objetivos.

\section{REFERÊNCIAS}

BARROS, Glória. O Setting analítico na clínica cotidiana. Estudos de psicanálise, Belo Horizonte, n. 40, p. 71-78, dez. 2013 . Disponível em: http://pepsic.bvsalud.org/scielo.php?script=sci_arttext\&pid=S010034372013000200008\&lng=pt\&nrm=iso. Acesso em: 26 dez. 2021.

BRASIL. Ministério da Saúde. Portaria no 639 de 31 de março de 2020. Disponível em: https://www.in.gov.br/en/web/dou/-/portaria-n-639-de-31-de-marco-de-2020-250847738. Acesso em: 26 dez. 2021.

CONSELHO FEDERAL DE PSICOLOGIA (Brasil). Resolução no 4, 26 de Março de 2020. Brasília, 30 mar. 2020. Disponível em: https://www.in.gov.br/en/web/dou/-/resolucao-n-4-de26-de-marco-de-2020-250189333. Acesso em: 31 dez. 2021.

\section{E - book Pesquisa e Tecnologia: Protagonismo e Inovações}


CONSELHO FEDERAL DE PSICOLOGIA (Brasil). Resolução n⿳0 11, 11 de Maio de 2018. Brasília, 14 maio 2018. Disponível em: https://www.in.gov.br/materia//asset_publisher/Kujrw0TZC2Mb/content/id/14132490/do1-2018-05-14-resolucao-n-11-de11-de-maio-de-2018-14132486. Acesso em: 31 dez. 2021.

MIGLIAVACCA, Eva Maria. Breve reflexão sobre o setting. Boletim de Psicologia, São Paulo, v. 58, n. 129, p. 219-226, dez. 2008. Disponível em:

http://pepsic.bvsalud.org/scielo.php?script=sci_arttext\&pid=S0006-

59432008000200009\&lng=pt\&nrm=iso. Acesso em: 26 dez. 2021.

ORGANIZAÇÃO PAN-AMERICANA DA SAÚDE. Histórico da pandemia de COVID-19. In: Histórico da pandemia de COVID-19. [S. l.], [2020 ou 2021]. Disponível em:

https://www.paho.org/pt/covid19/historico-da-pandemia-covid-19. Acesso em: 30 dez. 2021.

SCHMIDT, Beatriz et al. Saúde mental e intervenções psicológicas diante da pandemia do novo coronavírus (COVID-19). Estudos de Psicologia (Campinas) [online]. 2020, v. 37. Disponível em: https://www.scielo.br/j/estpsi/a/L6j64vKkynZH9Gc4PtNWQng. Acesso em: 26 dez. 2021.

WORLD HEALTH ORGANIZATION. Coronavirus disease: (COVID-19). In: Coronavirus disease . [S. l.], [2020 ou 2021]. Disponível em: https://www.who.int/healthtopics/coronavirus\#tab=tab_1. Acesso em: 30 dez. 2021. 